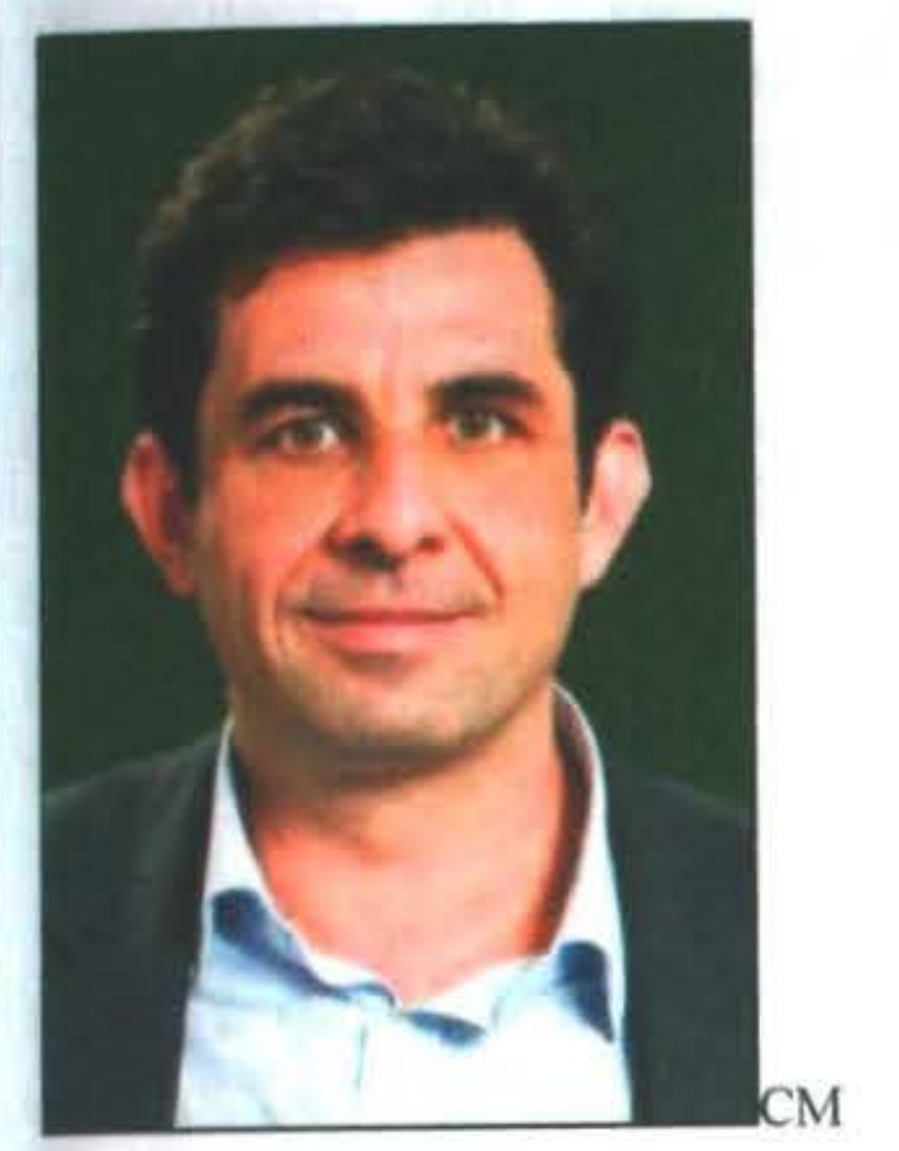

\title{
THE FRENCH CONNECTION: A MULTI-LINGUAL LITERATURE REVIEW OF OHS IN THE SMALL BUSINESS SECTOR
}

\author{
Christophe Martin, Franck Guarnieri \& \\ Jean Lin
}

CRC Ecole des Mines de Paris

\begin{abstract}
There is the growing recognition that Occupational Health and Safety (OHS) regulations and initiatives applied in the small business sector are frequently ineffectual. However, most of the discourse on OHS in the small business sector is ethnocentric with little or no insight into the relationship between the Anglo and French literature. This has meant that models of OHS intervention and prevention adopted by and/or adapted to the New Zealand small business sector are those that have been, by and large, written up in English. By excluding OHS intervention and prevention models or research on the basis that they are reported in a language other than English means that there is a potential of a myopic view on the subject. Moreover, given that workplaces are becoming more ethnically diverse, it is imperative that OHS models and research located in non-English speaking discourses are given due consideration. The purpose of this paper, therefore, is to provide a multilingual bridge between the English-speaking and the French-speaking research. In particular, the OHS literature written French, English and other languages will be reviewed in order to identify the major determinants of OHS risks in small businesses, thus providing a starting point for more comprehensive, preventative programmes aimed at all small businesses.
\end{abstract}

\section{Introduction}

The weight of the Small and medium-size companies (SMEs) has continued to grow in the economic setting since the end of $1970 \mathrm{~s}$. On average, more than $50 \%$ of the workforce is employed by these kinds of organisations in the industrialised countries. As the result of the externalisation of some their activities by the large companies and of a creed around the "small is beautiful", these organisations seem to provide the virtues of being flexible and innovative in a context of international competitiveness.

Over the same period, efforts with regards to risk prevention related to health and safety at work (OHS) increased and the management of these risks, which have been undertaken in these kinds of organisations, became a major concern for the services of the prevention.

In 1996, The Health and Safety Executive declared it almost impossible to improve health and safety at work in British companies without taking into account the specific issue of the small and medium-size enterprises (SME). The fact that there is clearly a gap between these organisations and large organisations in terms of occupational injuries, diseases and exposure of the workers to the OHS risks cannot, indeed, go unnoticed.

For all the member states of the European countries in 2000 (European Commission, 2003), companies of less than 250 employees represented $77.7 \%$ of the occupational injuries and $81 \%$ fatal injuries. In France,
$98 \%$ of the occupational injuries and $40 \%$ of the occupational diseases occurred in organisations of less than 200 employees (DARES, 2004). This over'accidentability' in SMEs and the over-exposure of the workers to differed risks, such as the dangerous chemical agents and the Carcinogenic, Mutagen products and Reprotoxiques (CMR), caused a strong growth of occupational diseases in these organisations, are thus at the origin of a main concern for the institutions of prevention.

Paradoxically enough, while SMEs has become a great focus of attention as an object of study in the sciences of management in the 80 s (Julien, 1997), the problems of safety and health in these organisations remained a marginal subject until very recently. Hasle and Limborg (2006), in a review of the literature on OHS prevention in SMEs, counted 284 relevant references among which 184 were in English, with a vast majority of these references $(71 \%)$ having been published between 1995 and 2004. Although the literature on the subject is not very abundant, it, nonetheless, cannot be said that there is a deficit of the scientific research. It appears, however, that there are few French studies and none explicitly referring to Anglo-Saxon literature and, more particularly, to New Zealand and Australian research. Moreover, as it has been noted (Favaro, 1996; Hasle and Limborg, 2006), research on health and safety in SMEs has suffered many repetitions and antagonisms. This article, thus, aims to present the problems SMEs must 
face with regards to OHS in the international context of growth of these companies. It, also, aims to classify the notions and concepts, which can constitute a theoretical basis for future empirical research as well as for the implementation of suitable preventive actions.

\section{The problem research}

The problems SMEs have to face with regards to OHS issues are interdependent from their economic contexts. This first part presents on the one hand, the main causes which have led to the growth of SMEs in industrialised countries as well as the features which mainly characterize them and, on the other, their poor performance with regards to OHS.

The authors will talk about the rebirth of SMEs from the 1970s (Julien, 1997). This rebirth took place in industrialised countries but extends also to the exsocialist countries in transition towards the market economy (Koradecka, 2001), which, for a long time, has privileged the large organisations. It further extends to the developing countries where their economy is largely based on the informal sector. In the United States and Japan, more than $2 / 3$ of the employees are employed by organisations of less than 250 people. In Europe, SMEs represented $99.8 \%$ of all organisations of the 25 member states in the European countries in 2003 (EC, 2002), that is to say $2 / 3$ of the workforce. By refining these figures according to the branch of industry, $10 \%$ of total organisations represents manufactured goods, $14 \%$ of total employment, the construction sector represents $13 \%$ of the total organisations and $9 \%$ of total employment. The retail sales sector represents $20 \%$ of total organisations and $14 \%$ of total employment.

With regards to the commercial non-financial economy, SMEs could generate more than half of the total of the gross-domestic product (GDP), indexed as follows: the 'micro-businesses' $20.5 \%$, small companies $19.1 \%$ and the medium-sized companies $17.8 \%$ (E.C, 2002).

In France, independent SMEs employing 0 to 249 people represented $55 \%$ of the total workforce in 2004 (employees and self employed-workers). Two-thirds of the workforce are employed in SMEs of less than 20 people and contribute to $66 \%$ of the GDP.

The reasons of this rebirth results, first of all, from a questioning of what has founded the myth of the large organisation: economies of scale, the results of the experience and training. Until very recently, the large organisations were regarded as the economic model to reach. SMEs were seen as small 'large companies' intended to grow. The 70 s and the oil crises modified the perception one had of this model.

The reasons are, however, not only economic, but also political and sociological.
Facing the employment crisis, the creation of organisations is a belief which one finds in many industrialised countries. The creation of small organisations was, in this context, supported by a legislative easing and suitable financings. However, as it will be seen later, the work contracts in small organisations are more precarious than in large ones.

On a sociological scale, the questioning of the large organisations coming from research of a more convivial work environment can also explain this passion for these organisations (Torres, 1999).

It would be, however, debatable to draw up a report based only on the model of "small is beautiful". Many authors are severe about small organisations and curb their enthusiasm towards the size of these organiastions. They are economically vulnerable and depend too much on their environment. A minor fact for a large company will become a considerable hindrance or an important problem in a SME (the loss of a customer which represents most of the sales turnover for example). This is the case for sub-contracting SMEs of a large organisation. Therefore, this economic vulnerability plays an important role in the level of prevention of $\mathrm{OHS}$ hazards.

SMEs show very different characteristics according to their contexts, raising problems and debates over the definition of the object of the study. Traditionally, one distinguishes the quantitative from the qualitative definitions.

When we talk about SMEs, the first criterion to be taken into account is the independence of the company. A small establishment controlled by a large company is not a SME (Julien, 1997). The problem particularly lies in certain forms of subcontracting.

The second criterion to be taken into account is the size of the workforce or the sales turnover. The notion of size can be very different according to the localisation of the company: less than 499/500 employees in some countries like the United States and France, and less than 100 people in other countries such as Austria and Norway.

In a recommendation dated May 6th, 2003 the European Union provides a quantitative definition of SMEs and classifies them according to the sales turnover and the size of the workforce. A SME is a company where manpower is lower than 250 people and sales turnover is lower than 50 million euros)

This quantitative definition proves insufficient when taking into account the complexity of SMEs as an object of research, and a certain number of authors have highlighted allowing the qualitative criteria to specify the quantitative definitions mentioned above. Julien (1997) has synthesised them in six criteria (table 1) 
Table 1: Criteria of SMEs among Julien (1999)

\begin{tabular}{|l|l|}
\hline Small size: & Less than 250 people \\
\hline $\begin{array}{l}\text { Centralized } \\
\text { management }\end{array}$ & $\begin{array}{l}\text { Personalisation of management } \\
\text { around the manager }\end{array}$ \\
\hline Low specialisation & $\begin{array}{l}\text { The employee's high degree of } \\
\text { polyvalence leads to a social } \\
\text { proximity }\end{array}$ \\
\hline $\begin{array}{l}\text { Low formalized } \\
\text { strategy }\end{array}$ & $\begin{array}{l}\text { Implementation of an intuitive } \\
\text { strategy due to the short } \\
\text { sightedness of SMEs whose } \\
\text { visibility is reduced in the long } \\
\text { term. }\end{array}$ \\
\hline $\begin{array}{l}\text { A poorly organized } \\
\text { internal information } \\
\text { system }\end{array}$ & $\begin{array}{l}\text { The internal information } \\
\text { network gives way to an } \\
\text { informal way of } \\
\text { communication }\end{array}$ \\
\hline $\begin{array}{l}\text { A simple external } \\
\text { information system }\end{array}$ & $\begin{array}{l}\text { The external information } \\
\text { network is made up of market } \\
\text { contacts, for e.g main : } \\
\text { suppliers, clients. }\end{array}$ \\
\hline
\end{tabular}

These characteristics thus highlight as many criteria of reliabilities as of vulnerability inherent in SMEs when facing hazards and must be taken into account to implement suitable preventive actions.

Concerning the vulnerability of these organisations, the statistics of the occupational diseases and injuries reveal a weak performance of SMEs compared to the large organisations (Favaro, 1996; Lamm 1999; Walters, 2001; Fabiano, 2004; Sorensen and Hasle, 2007)

While all the authors admit that it is difficult to establish comparisons between the large and the small organisations (Sorensen and Hasle, 2007), the international and French studies all state a higher risk of serious occupational injuries and fatal injuries in SMEs.

The European and French statistics highlight the relation between the size of the organistions and the frequency of occupational injuries and fatal injuries. The more the size decreases, a higher frequency rate is excepted for very small companies, which shows a lower frequency rate of occupational injuries but a higher percentage of fatal injuries. This is true for every country or group of countries which have been considered.

One notes, however, significant differences according to the studies among the risks which have been met. If the risks related to the handling and the exposure to chemicals are more often highlighted in the small organisations, it seems that they are less subjected to the psychosocial risks. This analysis is found in English and French studies on the subject. According to the ISAST (2006), organisations of less than 20 employees are, actually, penalised if one takes into account the various indicators on the physical efforts as well as the indicators of accidents and the indicators of hygiene (dirtiness, moisture).

\section{Prevention of risks in SMEs: internal and external factors}

The approach to the prevention of the risks in SMEs can be looked from both the internal and external factors of the organisation. The comparison of these various factors makes it possible to draw up a general representation of the determinants of the level of prevention of the occupational hazards in SMEs.

As seen in a preceding paragraph, SMEs are strongly conditioned by the actors of the organisation - the manager and the employees, but it also largely depends on its economic, social and legal environment. Research concerned with the undertaking and the implementation of measures related to occupational hazards in SMEs has, firstly, focused their attention on the actors of the organisation, more particularly on the manager, before highlighting the bonds between the level of prevention and the environment of the company.

The main focus of attention when considering the internal factors with regard to prevention is the manager. As seen previously, the manager's personality plays a key role in the management of the organisation. With regards to health safety at work, the manager's perception of hazards as well as the answers they bring about, is at the core of every author's preoccupation. Eakin (1992) has carried out one of the major studies on the matter.

Its first observation is that the majority of the managers of SMEs invest little in the management of health and safety at work. Most of the time, they consider that occupational hazards are related to the behaviours of employees and, more particularly, with their lack of prudency, vis-a-vis certain substances or dangerous situations

However, this behaviour of the employer is not monolithic and the results of the interviews reveal that the manager's position hinges around two very contrasting poles.

A minority pole (1/5 of the questioned leaders) which includes owners who state to take many efforts to take into account health and safety at work and claim they do not hesitate to take action against illegal or dangerous behaviour. This is what is called 'the coming down hard' approach.

A second pole, which is most widely spread, considers the prevention of the risks as the worker's problem. This is the "leaving it up to the workers" approach.

Knowing that this stance relates to two-thirds of the managers who have been interviewed, Eakin has tried to understand their reserved behaviour and reluctance to handle OHS matters. Two main explanations may justify this behaviour. 
One explanation lies in the way social relations are woven in SMEs, which appears completely different from what may be observed in large organisations. The employer-employee relationship has a family dimension and is less polarised than in large organisations.

The other explanation lies within the perception of the manager's responsibility which could either be considered as personal or merely bureaucratic. Employers are not really aware (or very little) that they are legally responsible. They are also not aware of their duties as far as OHS is concerned. They tend to think they cannot call some of their employees' practices into question without casting doubts over their skills. Therefore, as stated by the author, the peculiarity of the context in SMEs calls for a management of occupational health and safety as the employee is considered as being at the core of the problem, perhaps the problem in itself.

This vision of the small organisation of less than 50 people is confirmed by a more recent survey by Champoux and Brun, (2000), who proposed to describe the representations of OHS management by the employers in SMEs of less than 50 employees. This study made it possible to carry out three principal observations.

First is that contrary to widespread belief, there exists a management of occupations hazards in SMEs, even if this one is not at the level expected by the legal authorities.

The second observation was about the manager's perception of the level of prevention in their company. On the whole. the manager is said to be satisfied with the level of prevention in their company and after having crossed all the information, the survey shows that the managers are cut off from the prevention supply and do not know the statutory regulations.

The third links the conclusions of Eakin (1992): managers impute blame for their employees for two third of the accidents.

Taking into account the internal factors of SME and more particularly of the head of undertaking is thus an important way of research. It cannot, however, exclude the organisation's environmental factors, which plays a determining role of the level of prevention.

The approach by the external factors is found in Favaro (1997) and Walters's research.

Far from denying the role of decision making, Favaro starts from the hypothesis that the practices concerned with the prevention depend mostly on factors different to those linked to OHS, such as SMEs' independence, their financial and juridical structure, but also their economic situation and the bonds they can have with quality management. A very detailed questionnaire taking into account numerous variables allowed Favaro to have a very accurate overview of the situation in SMEs and their dealings with occupational and safety risks.
The first observation made is that of a chasm between the organisations that have implemented different practices with regards to OHS management and those that have shown a total lack of preventive actions. The most widespread group is the one in which organisations are inactive. The effect of size combined with the organisation's inactivity has clearly shown that inactivity is the rule for organisations of less than 40 workers and that the situation improves for organisations of about one hundred employees.

As for the bond between the degree on independence of a organisation and its inactivity with regards to hygiene and safety matters, the result of the study have shown that structural independence is in close correlation with a higher rate of inactivity. The contrary, too holds correct, the less independent a company is, the more active it is. Therefore the degree of independence strengthens inactivity in terms of hygiene and safety as demonstrated by Favaro.

"A company with little workforce, technically noncomplex and a fortiori structurally independent shows a configuration particularly unfavourable to the implementation of preventive actions" (Favaro, 1997:79).

With regards to the relationship between the economic context of the organisation and its professional environment, the study has shown that the more favourable the position of the organisation was, the better the level of safety became.

The distance between the relationship with a quality management team also plays a significant role in an organisation's commitment to the process of prevention of occupational risks. This may be explained through the similar practices between the method of quality certification and the assessment of occupational risks. The authors, however, remain evasive about this last statement.

The general conclusion of the study is that the external determinants which hold with the context of the company (economic situation in particular) are more determining than the internal factors (technology, profile of the leader, type of organisation) to understand the various levels of the measures undertaken in OHS matter.

The determination of a level of prevention of the risks by contextual elements is an assumption also raised by Walters (2001). This latter in an European investigation presents the various ways of prevention in SME.

After having pointed out the internal factors which support prevention, Walters presents the contextual elements which play, according to him, a fundamental role to exert an external pressure on SMEs. Namely, the large organisations of the sector, the organisation's customer, the consumers, the services of prevention, the consultants in health and safety and wage earners 
associations which both put support and pressure on the employees. He confirms research which had pleaded for an approach of organisations complementing the services of prevention through the role of the intermediaries. This operates as a role of translation of the regulation for the leaders of SMEs, it is in particular the case of the chartered accountants in the side door approach (Lamm, 1997) and of the chambers of commerce as an actors' relay (Grosjean, 2003).

In addition, many preventive actions are based on the proximity between large organisations, which have already implemented tools and methods of prevention of occupational hazards and the small organisations.

Walters (2001) gives examples of this type in the various countries of the European Union, particularly in the United Kingdom, where a program entitled "Good neighbourhood" was launched in the 1990s by the Health and Safety Executive (HSE). This was to encourage the large organisations to deal with their counterparts by the means of common seminars, sharing of experiments and provisioning of expertise in this field.

This positive role of the large organisations on the small ones partly confirms of Favaro's analysis (1997). However, it is not shared by all the community.

In France, the low level of compliance of sub-contractors is deplored by many clients particularly in the building industry. The latter gives a report on the little influence that they have on the small organisations in a sector where a vast majority of the activities are carried out by subcontracting. This observation is confirmed by many researchers who report the negative relation existing between the level of prevention of the OHS risks in small organisations and their dependence with respect to large organisations (Mayhew and Quinlan, 1997). This deterioration of health and safety at work finds its source in the economic pressure which prevails in this type of relations. One of the reasons of subcontracting is, indeed, for a reduction in production costs.

The corporate network, thus, has a positive impact on the manager, the level of prevention of the OHS risks when the institutional context supports the information exchanges. However, the dependence of the subcontractors with respect to the clients can be at the origin of a degradation of the prevention when the large companies outsourcing their risks.

The research presented above makes it possible to draw up a general representation of the determinants of health and safety with work in this type of organisations.

Internally, the manager whose profile of management is determined by their level of studies, their expectation as a contractor, their insertion in a network and their financial resources adopts an attitude which can go from the lowest level of conformity to the fullest (the most general attitude being to leave it to the employee) (Eakin, 1992; Lamm 2001).

The attitude of the employees varies according to their qualifications, their skills and their situation toward employment. Precarious employment is a key factor to understanding the level of prevention of risks, but this precarious employment also depends on the economic context of the organisation (Quinlan, 1997).

In addition, the specific context of the employers/employees social relations in small organisations must be taken into account and does not allow the same thinking on prevention as in large organisations. The positioning of the employers with respect to their employees does not enable them to use the means of pressure which can be required of a leader of a large organisation (Eakin, 1992).

Externally, the weak bond with the institution and the relation between dependence and the organisation's customer can maintain a level of low prevention.

In other cases, the relation of dependence can lead to an appropriation of risk measurement management implemented by the client and deciding the best way of taking into account OHS matters (Walters, 2001).

Herein, the legal, social and economic environments play a determining role and, therefore, must be taken into account to include and understand how they interact with these internal determinants. These interactions are different according to the identity card from the company (Favaro, 1997) (effective, legal independence and the market in which it operates) and the attitude of the manager facing regulation (Lamm, 2001).

\section{Conclusion}

The different international research presented in this article gives an overview of the results which, independently of the economic and cultural contexts in which SMEs are bathed and developed, may be regarded as international factors on the level of prevention in SMEs. All the research, which has been carried out so far, is nonetheless largely localised in the Anglo-Saxon countries and in Northern Europe, and it seems in the light of the publication that the international collaborations have been fertile.

The relative French insulation in this field and the poor references on the subject should urge a greater interest towards international research. Moreover, all the research which has been carried out in France confirms the results of the international research (Favaro, 1997; ISAST, 2006). A recent qualitative research project carried out during the assessment of an experimental preventive action by Martin and Guarnieri, 2007 has authenticated in French SMEs, the international invariants presented in this paper. The invariants are classified into five categories; the attitude of the 
manager, the perception of the role of the institutional dealing with prevention, the impact of the organisation's environment and its stage of economic development. They should be used as a basis to develop other preventive actions which take into account the ways which have been opened by (Lamm, 1997; Hasle, 2000; Antonsson; 2001; Walters, 2001).

There is, therefore, a need for collaboration in order to go beyond the mere conclusion of a vulnerability of SMEs facing OHS hazards and a techno-centred vision of the problem. What is more, research on the subject must be anchored in the conceptual knowledge of these organisations and may constitute starting points towards the implementation of preventive actions. French research (Julien, 1997; Marchesnay, 2000) may shed some significant light on the subject.

\section{References}

Antonsson, A.B. (1997). Small Companies. In D. Brune, G. Gerhardsson., G.W. Crockford and D, Norback. (Eds). The International Labour Office (pp. 466-477). Oslo: Geneva and Scandinavian Science Publisher.

Champoux, D. and Brun, J-P. (1999). Prise en Charge de la Sécurité dans les Petites Etablissements des Secteurs de L'Habillement et de la Fabrication des Produits en Métal. (Rapport R-226). Québec, Canada: Institut de Recherches en Santé et Sécurité du Travail du Québec (IRSST)

Eakin, J. (1992), Leaving it up to the workers: Sociological Perspective on the Management of Health and Safety in Small Workplaces. International Journal of Health Services, 22: 689 $-704$

Fabiano, B. and Curro, F. (2004). A study of the relationship between occupational injuries and firm size and type in the Italian industry. Safety Science 42, 587-600

Favaro, M. (1996). La prévention dans les PME Position du problème-examen de la littérature. Les notes scientifiques de L'INRS

Favaro, M. (1999). La prise en charge de la sécurité dans les PME: Quelques Réflexions Préalables à la Conception d'actions de Prévention. Les notes scientifiques et techniques de l'INRS

Favaro, M. (1999). La prise en charge de la sécurité dans les PME: Quelques Réflexions Préalables à la Conception d'actions de Prévention. Les notes scientifiques et techniques de l'INRS

Grosjean, V. (2003). Comment Favoriser Chez les Chefs d'Entreprises un plus large prise en compte de la prévention? Perspectives Théoriques et
Pragmatiques. Cahiers des Notes Documentaires - Hygiène et Sécurité du Travail. 190 : 51-65

Hasle, P. and Limborg, H.J. (2006). A Review of the Literature on Preventive Occupational Health and Safety in Small Enterprises. Industrial Health. 44(1): 6-12

Hasel, P., Kines, P. and Anderson, P.L. (2008). Small enterprise owners' accident causation attribution and prevention. Safety Science. 47(1): 9-19

ISAST. (2006) Les pratiques et les politiques de prévention des risques professionnels dans les très petites entreprises, étude commandée par la DARES

Julien, P. A, 1997. Les PME bilan et perspectives. Ed Economica, Paris

Koradecka, D. (2001). Occupational Safety and Health in Small and Medium-Sized Enterprises during Social and Economic Transformation. International Journal of Occupational Safety and Ergonomics. 7(1): 3-14

Lamm, F. (1997). Small Businesses and OHS Advisors. Safety Science. 25(1-3): 153-161

Lamm, F. (1999). Occupational Health and Safety in Australian Small Businesses: What can be done to reduce the lack of awareness and raise the level of compliance in Australian Small Businesses? National Occupational Health and Safety Commission. Canberra

Lamm, F. (2002). Occupation Health and Safety in Small Businesses. In M. Lloyd (Ed). Occupational Health and Safety in New Zealand. Contemporary Social Research. Wellington: Dunmore Press

Lamm, F. and Walters, D. (2004). OHS in Small Organisations: Some Challenges and Ways Forward. In L. Buff., N. Gunningham., R. Johnston, R. (Eds). OSH Regulation for the $21^{\text {st }}$ Century. (pp. 94-120). Sydney: Federation Press.

Marchesnay, M. (2000). L'Entrepreneur face à ses risque. Revue Innovation. Cahier d'économie de l'innovation. 12: 27-57

Martin, C. and Guarnieri, F. (May, 2007). Bilan et enseignements de l'action collective "santé et sécurité dans les PME-PMI " Rapport Interne de Recherches. Mine de Paris

Mayhew, C. and Quinlan, M. (2001). The effect of changing patterns of employment on reporting occupational injuries and making worker's compensation claims. Safety Science Monitor. $5(1): 22-27$ 
Sorensen, O., Hasle, P. 2007. Working in small enterprises-Is there a special risk? Safety Science 45 : 1044-1059

Torres, O. (1999). Les PME. Ed Flammarion, Collection Dominos. 128

Quinlan, M. (1997). The Implications of labour market restructuring in industralised societies for occupational health and safety. Working paper no.116. School of Industrial Relations and Organisational Behaviour. University of New South Wales: Australia.

Walters, D. R. (2001). Health and Safety in Small Enterprises. European Strategies for Managing Improvement. P.I.E-Peter Lang. S.A, Brussels.

\section{Authors}

Christophe Martin

CRC Ecole des Mines de Paris

Rue Claude Daunesse

France

CMartin@isaip.org

Frank Guarnieri

CRC Ecole des Mines de Paris

Rue Claude Daunesse

France

Frank.Guarnieri@ensmp.fr

Jean Lin

CRC Ecole des Mines de Paris

Rue Claude Daunesse

France

jeannelin.27@gmail.com 